\title{
A INSERÇÃO DO DEFICIENTE NO MERCADO DE TRABALHO
}

Jerson Joaquim da Silva

Universidade do Oeste Paulista - UNOESTE, curso de Administração, Presidente Prudente, SP. E-mail: jersonjsilva@hotmail.com

\section{RESUMO}

Nesta pesquisa é relatada a responsabilidade que as empresas têm para acolherem, de melhor forma, as pessoas com deficiência, buscando o cumprimento de leis, mas também colaborando a serem inseridas como cidadãos ativos na economia do País; oportunizando para essas pessoas bens psicológicos e realização pessoal. Esta pesquisa teve como objetivos analisar de qual maneira as organizações podem se preparar para a inserção da pessoa com deficiência; verificar como os funcionários estão preparados para acolher as pessoas que deficiência; entender o que motiva o interesse das empresas para buscar inserir as pessoas com deficiência e observar quais procedimentos necessários e recursos utilizados no ambiente de trabalho para receber e adaptar de melhor forma a pessoa com deficiência. O método utilizado para realizar a pesquisa foi o exploratório, com base em estudos bibliográficos, baseando-se em uma pesquisa qualitativa. A pesquisa revelou que, ainda, há resistência das organizações para contratação de colaboradores que possuem alguma deficiência.

Palavras-Chave: Deficiência. Mercado de trabalho. Organizações. Inserção.

\section{THE INSERTION OF THE DISABLED IN THE LABOR MARKET}

\section{ABSTRACT}

This research is reported the responsibility that companies have to accommodate, best way, people with disabilities, seeking the enforcement of decrees, but also helping to be inserted as active citizens in the country's economy, providing opportunities for those goods and personal psychological. This research aimed to analyze how organizations can prepare for the insertion of the disability; see how employees are prepared to accommodate the disabled; understand what motivates the interest of companies to get insert the disabled and observe what procedures and resources used in the work environment to receive and better adapt the disability. Themethod used to conduct the survey was exploratory in the bibliographic studies, based on a qualitative research. The research revealed that there is still resistance of organizations for hiring employees who have some disability.

Keywords: Disabilities. The labour market. Organizations. Insert.

\section{INTRODUÇÃO}

Por meio deste estudo, pretendeu-se elucidar a questão da inserção no mercado de trabalho de pessoas com deficiência. Por meio da adaptação dessas pessoas, torna-se possível perceber a importância incontestável para a economia do País, onde se gera mais empregos e sucessivamente rendas, influenciando no poder de aquisição, gerando novos consumidores que não estavam ativos.

No mundo contemporâneo fica mais difícil imaginar que pessoas são excluídas do meio social em razão das características físicas que possuem, como cor da pele, cor dos olhos, altura, peso e formação física. As pessoas já nascem ou se transformam com essas características e não 
podem ser consideradas culpadas por tê-las. Mesmo com características que as tornam aptas a serem trabalhadores, com todas as condições para o cumprimento de suas funções, torna-se difícil $o$ ingresso no mercado de trabalho.

No contexto atual, o estado perfeito físico não traz vantagens para o trabalhador, entretanto os trabalhadores que possuem certa deficiência sejam elas físicas ou mentais, podem encontrar determinadas dificuldades para inserção e validade da sua real utilidade no mercado.

Nesse sentido, este trabalho procurou apontar, com base em referencial teórico, as dificuldades e oportunidades que as pessoas de deficiência têm em relação aos preconceitos e desafios por eles enfrentados.

Se por um lado existe a inclusão, existe o contraponto da exclusão social por outro, e entende-se que a exclusão está ligada a todas as pessoas que não têm as mesmas oportunidades dentro da sociedade. Esses excluídos, socialmente, são também os que não possuem condições financeiras favoráveis, decorrente de padrões físicos conquistados no decorrer da história humana e tomado como base na sociedade, pois além das pessoas com deficiência, como cadeirantes, deficientes visuais, auditivos e mentais, existem outros exclusos, como os idosos e os negros.

Sabe-se que o trabalho tem o intuito de apresentar o bem psicológico que a oportunidade de tal adaptação gera para essas pessoas com deficiências. Essas vagas são ofertadas buscando a inclusão de pessoas que antes eram vistas como incapazes, e excluídas do mercado de trabalho.

É dado como novo desafio a ser ultrapassado por elas, já que estão sempre em constantes obstáculos em seu dia-a-dia, podendo despertar suas habilidades e capacidades como qualquer outro cidadão. Esse processo pode trazer auto realização e interação social, desenvolvendo o comprometimento e a satisfação desse trabalhador em se sentir útil.

A pesquisa buscou demonstrar as leis de cotas que devem ser cumpridas, os benefícios e inovações para dentro do ambiente organizacional com a contratação desse trabalhador com deficiência. Como empresas buscam meios de recrutamento de pessoas com deficiências, a capacitação dessas pessoas passa a ter importância na gestão, na superação de desafios e diversidades que os administradores enfrentam para as adaptações culturais, estruturais, como a acessibilidade, e as relações interpessoais da equipe de trabalho.

Esta pesquisa se justifica porque vê a finalidade de mostrar a importância da inserção de pessoas com deficiência no mercado de trabalho. Muitas pessoas com algum tipo de deficiência não podem viver em condições de dignidade devido a obstáculos e barreiras no ambiente onde vivem, principalmente no âmbito organizacional.

Desse modo, elencou-se o objetivo geral, que está diretamente ligado ao tema do estudo, tratando de forma abrangente e generalizada a pesquisa realizada.

Este trabalho teve como objetivo geral analisar de qual maneira as organizações podem se preparar para a inserção do deficiente e como objetivos específicos verificar como os funcionários estão preparados para acolher os deficientes; entender o que motiva o interesse das empresas para buscar inseri-los e observar quais os procedimentos necessários e recursos utilizados no ambiente de trabalho para receber e adaptar de melhor forma deficiente.

\section{METODOLOGIA}

Esta pesquisa teve uma abordagem qualitativa, pois foi uma pesquisa bibliográfica. Para coleta de dados, foram utilizados livros que contemplaram o assunto, bem como sites, artigos, monografias e dissertações que tratam da temática. Também é uma pesquisa exploratória pois à medida que o assunto ia sendo desvendado, foi explorado pelas autoras. É descritiva, pois conforme vai se entendo o assunto o mesmo teve novo sentido através da descrição que será apresentado. 
O método de abordagem utilizado nesta pesquisa foi qualitativo, pois reduz a distância e traz para mais próximo a teoria e os dados e transformam em apenas um só conteúdo, onde pode expressar a realidade do mundo social, ou seja, nos leva a mais fácil interpretação (MAANEN, 1979).

\section{RESULTADOS}

Quanto à acessibilidade, a pesquisa revelou que cabe às empresas darem todo o suporte necessário para que a pessoa com deficiência trabalhe da maneira mais confortável a fim de que ela dê o seu melhor. "A pessoa deixa de ser deficiente no momento que a sociedade proporciona condições adequadas" (PASTORE, 2000, p. 13). Sem condição de trabalho, nem o mais brilhante funcionário irá trabalhar da melhor maneira possível.

Todos nós, naturalmente, circulamos pelas ruas e, para que as pessoas com algum tipo de deficiência, limitação, também tenham o direito de ir e vir, garantindo sua vida em sociedade, é indispensável que as cidades sejam bem planejadas, de forma acolhedora, que não se tenha apenas uma arquitetura de fachada, bonitinha e fria. (LICHT e SILVEIRA, 2010, p. 60).

A acessibilidade fora das organizações ainda é um problema. O caminho percorrido para que a pessoa com deficiência chegue ao ambiente de trabalho não é melhor e deve ser melhorado. $O$ cadeirante, por exemplo, sofre por não ter guias rebaixadas em todos os lugares ou com asfalto em péssimas condições para locomoção. Ainda é algo a ser trabalhado e solicitado ao Estado.

Quando a empresa resolve contratar pessoas com deficiência deve estar pronta para adaptar-se a algumas mudanças corporativas e em seu ambiente físico. "A preparação do ambiente de trabalho envolve providências físicas, educacionais e sociais" (PASTORE, 2000, p. 213).

As adaptações devem partir de treinamentos corporativos a alterações no ambiente físico, de maneira que tudo facilite para que aquele trabalhador possa cumprir suas tarefas sem nenhum obstáculo físico nem psicológico.

A empresa deve se atentar para o espaço físico, adaptando sua estrutura física de acordo com as necessidades apresentadas para a inclusão desses trabalhadores PCDs, para cumprir o estabelecido em Lei.

Muitas empresas já possuem sua estrutura física de acordo com a acessibilidade pelo fato de já se cumprirem a "lei de cotas" para a inserção desses trabalhadores, adaptando todos os setores da empresa. O intuito das mudanças é ter o nível recomendado de acessibilidade, destruindo barreiras arquitetônicas que possam vir a prejudicar o desemprenho das atividades ou a locomoção do PCDs dentro da organização.

Há alguns anos, as organizações não procuravam pessoas que possuíam algum tipo de deficiência para trabalhar, havendo certos preconceitos em relação à contratação dos deficientes no mercado de trabalho. A ONU (Organização das Nações Unidas) declarou o ano de 1981 como "Ano Internacional das Pessoas Deficientes" a fim de que os deficientes tivessem as mesmas oportunidades que não possuem deficiências. Foi então que os países começaram a se voltar aos deficientes, e dar uma chance maior de se desenvolver e crescer dentro das empresas.

Segundo Sassaki (1997, p. 41) a inclusão social é definida como:

O processo pelo qual a sociedade se adapta para poder incluir, em seus sistemas sociais gerais, pessoas com necessidades especiais e, simultaneamente estas se preparam para assumir seus papéis na sociedade. A inclusão social constitui, então, um processo bilateral no qual 
as pessoas, ainda excluídas, e a sociedade buscam, em parceria, equacionar problemas, decidir sobre soluções e efetivar a equiparação de oportunidades para todos.

A maneira como agem e convivem as pessoas no meio social se dá pelos seus valores, crenças e cultura, se cria preconceitos e conceitos da inserção de pessoas com deficiências no mercado.

De acordo com Pastore (2000), há muita generalização equivocada, pelo fato de a sociedade confundir limitações relativas da vida diária, com limitações de integração no meio social e capacidade de estar trabalhando como qualquer outra pessoa diferente daquilo que para cada um é comum.

O mundo capitalista em que as pessoas estão inseridas requer para organizações pessoas qualificadas cada vez mais, ocasionando a desigualdade social e alavancando desemprego, gerando disputas por vagas de emprego, dificultando ainda mais a inserção de pessoas com deficiências no mercado.

Como qualquer outro indivíduo, as pessoas com deficiência possuem uma vida própria e comum. "Como ocorre com todos os seres humanos, a vida dos portadores de deficiência é cercada de alegrias, realizações, incertezas e dificuldade" (PASTORE, 2000, p.13). Em algum momento da vida, todas as pessoas, independente de possuir deficiência ou não, terão motivos para sorrir ou chorar.

\section{DISCUSSÃO}

A inclusão traz mudanças no ambiente organizacional e muitos gestores têm medo do desconhecido, fazendo com que posterguem a inclusão dos deficientes em suas organizações.

Ainda, há resistência das organizações para contratação de colaboradores que possuem alguma deficiência.

Contudo, as organizações podem se preparar oferecendo treinamento aos colaboradores de como se portar frente a esse novo colaborador, das futuras dificuldades que possam vir a ter e como eles poderão ajudar quando solicitado, ou até mesmo quando não solicitado, mas achar que tiver necessidade. Em caso de um deficiente auditivo viesse a fazer parte do quadro de colaboradores da empresa, os demais poderiam aprender a linguagem de sinais para que pudessem ter comunicação entre todos os funcionários, ou o cadeirante tivesse acesso a todos os lugares para livre locomoção.

Os deficientes precisam sentir-se à vontade, esquecendo-se da deficiência que possuem, para que desenvolvam um trabalho igual ou melhor que qualquer outro colaborador, e se tornem funcionários resilientes dentro da organização, transformando dificuldades em oportunidades e agregando valor à empresa.

A exclusão que por intermédio da história foi atribuída a pessoas com deficiências deve ser vencida através da inserção de leis constitucionais e pela conscientização de todo entorno social sobre a verdadeira capacidade de cada indivíduo.

Esta pesquisa propõe colocar questionamentos sobre o assunto abordado e destacar pontos cruciais, sem a pretensão de sana-los. Sendo assim, de maneira oposta, a expectativa imposta a este trabalho é de que os estudos realizados sirvam para dar incentivo em outras interrogações e pesquisas.

As organizações devem analisar de forma completa a inserção de pessoas com deficiência no mercado de trabalho, sobre a observação das suas qualidades e não sobre as suas limitações para o trabalho. 
Da mesma forma, quando determinada pessoa apresenta seu currículo não se questiona o que se ele sabe fazer, mas se está apto com o cargo disponível e se o seu perfil é o mais compatível com o profissional a ser escolhido.

\section{CONCLUSÃO}

De modo geral, a conclusão é de que as pessoas com deficiência atualmente estão pareadas em termos de igualdade de capacitação, competência e desempenho, porém ficou claramente compreendido que a inclusão das PCDs não ocorreu completamente, pois mesmo no confronto diário com pessoas com deficiência que estejam empregadas, percebe-se que as organizações não compreendem completamente o valor do trabalho para esta parte da população, onde estes são vistos como pessoas de necessidades especiais, vinculando a percepção para a necessidade em todas as tarefas que o mesmo realize.

Além das leis necessárias para que os direitos das pessoas com necessidades especiais, evidencia a necessidade de efetivação real das leis já criadas, alocar um maior volume de informação para os funcionários das organizações sobre os PCDs, um maior cuidado com a qualidade dos colaboradores e uma extinção do preconceito.

É considerado essencial que as ações do gestor proporcionem a esta parte da sociedade a conclusão de seus direitos, proporcionando oportunidades igualitárias, não utilizando a inserção como marketing organizacional ou para se adequar aos padrões exigidos pela justiça, ou seja, utilizar destes artifícios para beneficiar os indivíduos da parte da sociedade em que a empresa atua e não como benefício organizacional.

Nesse ponto as PCD's não solicitam diferenciação de analises e de benefícios, e sim a igualdade de condições com os demais indivíduos da empresa. Para que isso ocorra, é necessário adequar a acessibilidade, o local público e privado também deve comportar a todos e não ser reservado a apenas alguns. Por fim, proporcionar condições a estes é divulgar a justiça na sociedade e ser superior as diferenças e desigualdades.

\section{REFÊRENCIAS BIBLIOGRÁFICAS}

BRASIL. CONSTITUIÇÃO DA REPÚBLICA FEDERATIVA DO BRASIL DE 1988. Disponível em: <http://www.planalto.gov.br/ccivil 03/Constituicao/Constituicao.htm>Acesso em: 20. Ago. 2015.

BRASIL. DECRETO № 3.298, DE 20 DE DEZEMBRO DE 1999. Regulamenta a Lei no 7.853, de 24 de outubro de 1989, dispõe sobre a Política Nacional para a Integração da Pessoa Portadora de Deficiência, consolida as normas de proteção, e dá outras providências. Disponível em: http://www.planalto.gov.br/ccivil 03/decreto/D3298.htm Acesso em 21. Ago 2015

BRASIL. LEI № 7.853/89 DE 24 DE OUTUBRO DE 1989. Dispõe sobre o apoio às pessoas portadoras de deficiência, sua integração social, sobre a Coordenadoria Nacional para Integração da Pessoa Portadora de Deficiência - Corde, institui a tutela jurisdicional de interesses coletivos ou difusos dessas pessoas, disciplina a atuação do Ministério Público, define crimes, e dá outras providências. Disponível em: <http://www.planalto.gov.br/ccivil 03/LEIS/L7853.htm> Acesso em 21. Ago 2015

BRASIL. LEI № 8.213, DE 24 DE JULHO DE 1991. Dispõe sobre os Planos de Benefícios da Previdência Social e dá outras providências. Disponível em: <http://www.planalto.gov.br/ccivil_03/LEIS/L8213cons.htm> Acesso em 21. Ago 2015

BRASIL. LEI N. 10.098, DE 19 DE DEZEMBRO DE 2000. Estabelece normas gerais e critérios básicos para a promoção da acessibilidade das pessoas portadoras de deficiência ou com mobilidade 
reduzida, e dá outras providências. Disponível em: <http://www.planalto.gov.br/ccivil 03/LEIS/L10098.htm>. Acesso em: 20. Ago. 2015.

CLEMENTE, C. A. S. S. O. Trabalho de pessoas com deficiência e Lei de Cotas: Invisibilidade, resistência e qualidade da inclusão. Osasco, SP. 2015.

Consumidor brasileiro valoriza responsabilidade socioambiental da empresa Disponível em: <http://www.ipea.gov.br/acaosocial/articleabf3.html?id article=356> Acesso em: 05 nov. 2015

EMPREgA SÃO PAULO. Programa de Apoio à Pessoa com Deficiência. Disponível em: <http://www.emprego.sp.gov.br/emprego/programa-de-apoio-a-pessoa-com-deficiencia/>Acesso em: 07 nov. 2015.

FROES, C. Responsabilidade Social e Cidadania Empresarial: A Administração do Terceiro Setor. Rio de Janeiro: Qualitymark Editora, 2005.

KARKOTLI, G. Responsabilidade Social Empresarial. Petrópolis: Vozes, Editora, 2006.

LICHT F. B. S. N. Celebrando a diversidade: Pessoas com Deficiência e Direito à Inclusão São Paulo, 2010. Disponível em: <http://www.planetaeducacao.com.br/portal/Celebrando-Diversidade.pdf>. Acesso em: 02 out. 2015.

Memorial da inclusão. Disponível em: <http://www.memorialdainclusao.sp.gov.br/br/home/aipd.shtml>. Acesso em: 29 fev. 2016.

NAMBU, T. S. Construindo um mercado de trabalho inclusivo: guia pratico para profissionais de recursos humanos. São Paulo: SORRI-BRASIL; Brasília: CORDE, 2003.

MAANEN, J. V. Reclaiming qualitative methods for organizational research: a preface. v.24. In Administrative Science Quarterly, 1979.

OLIVEIRA, J. A. P. Empresas na sociedade: Sustentabilidade e responsabilidade social. Rio de Janeiro: Elsevier, 2008.

ORGANIZAÇÃO INTERNACIONAL DO TRABALHO. Adaptação de ocupações e o emprego do portador de deficiência. Tradução de E. A. da Cunha. Brasília, DF: CORDE, 1997. 182 p.

PASTORE, J. Oportunidades de trabalho para pessoas de deficiência. São Paulo: LTr, 2000.

RIBAS, J. B. C. As pessoas portadoras de deficiência na sociedade brasileira. Brasilia: Corde, 1997.

SASSAKI, R. K. Inclusão: construindo uma sociedade para todos. Rio de Janeiro. WVA, 1997. 